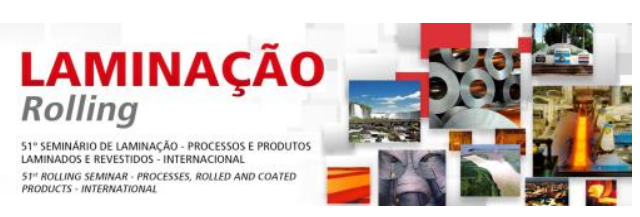

\title{
EFEITO DAS CONDIÇÕES DE TRATAMENTO DE GALVANNEALING NA QUALIDADE DO REVESTIMENTO GALVANNEALED EM AÇOS BAKE HARDENABLE*
}

\section{Resumo}

Aldo Henrique de Almeida Barbosa ${ }^{1}$ Sandra Goulart-Santos ${ }^{2}$ Vicente Tadeu Lopes Buono ${ }^{3}$

Dentre os revestimentos galvanizados a quente, o galvannealed (GA) destaca-se por possuir uma estrutura composta por fases $\mathrm{Fe}-\mathrm{Zn}$, o que the confere excelente desempenho na aplicação em peças de alta solicitação. A qualidade do revestimento GA é governada principalmente pelo tratamento de galvanneling, tendo em vista seu efeito na formação dos compostos Fe-Zn. A influência desse tratamento é ainda mais pronunciada em aços com características de bake hardenability $(\mathrm{BH})$, pela presença de elementos que alteram a sua reatividade. Nesse estudo, foram avaliados os efeitos das condições de galvannealing na formação do revestimento GA sobre aços $\mathrm{BH}$. Para tal, ciclos de galvannealing variando-se a temperatura de aquecimento entre $530^{\circ} \mathrm{C}$ e $580^{\circ} \mathrm{C}$ foram simulados em escala de laboratório. Além dos ciclos completos, foram também realizadas interrupções do tratamento ao longo da etapa de encharque, através de resfriamentos bruscos das amostras, com o objetivo de avaliar a microestrutura do revestimento ao longo de todo o tratamento. Os resultados permitiram determinar os mecanismos de formação e crescimento dos compostos intermetálicos Fe-Zn que constituem o revestimento galvannealed, e correlacioná-los com as características do produto final, de maneira a estabelecer faixas adequadas de processamento desse material.

Palavras-chave: Aço galvannealed; Tratamento de galvannealing; Simulador de galvanização a quente.

\section{EFFECT OF GALVANNEALING CONDITIONS IN THE QUALITY OF GALVANNEALED COATINGS FORMED ON BAKE HARDENABLE STEELS \\ Abstract}

The galvannealed coated (GA) is distinguished by having a structure containing Fe-Zn phases, which gives it excellent performance on highly demanding applications. The coating quality is determined by the galvannealing treatment, because of its effects on Fe-Zn compounds formation. The treatment influence is even more pronounced in bake hardenable steels, due the presence of alloying elements that change their reactivity. In this study, the effects of different galvannealing conditions on the GA coating formation on $\mathrm{BH}$ steels were evaluated. For this, galvannealing cycles at temperatures varying from $530^{\circ} \mathrm{C}$ to $580^{\circ} \mathrm{C}$ were simulated in laboratory scale. In addition to the completed cycles, interrupted cycles were also carried out, stopping the cycle during the soaking step by quenching the samples, aiming to evaluate the microstructure throughout the whole treatments. The results allowed determining the nucleation and growth mechanisms of the $\mathrm{Fe}-\mathrm{Zn}$ intermetallic compounds, and correlating them with the characteristics of the final product, in order to establish appropriate ranges for processing this material.

Keywords: Galvannealed steel; Galvannealing treatment; Hot dip galvanizing simulator.

1 Engenheiro Metalurgista, Doutor em Engenharia Metalúrgica e de Materiais, Pesquisador Especialista do Centro de Tecnologia Usiminas, Ipatinga, MG, Brasil.

2 Engenheira Química, Doutora em Engenharia Metalúrgica e de Materiais, Pesquisadora do Centro de Tecnologia Usiminas, Ipatinga, MG, Brasil.

3 Físico, Doutor em Engenharia Metalúrgica e de Minas, Professor do Departamento de Engenharia Metalúrgica e de Materiais da EEUFMG; Belo Horizonte, MG, Brasil.

* Contribuição técnica ao $51^{\circ}$ Seminário de Laminação - Processos e Produtos Laminados e Revestidos, 28 a 31 de outubro de 2014, Foz do Iguaçu, PR, Brasil. 


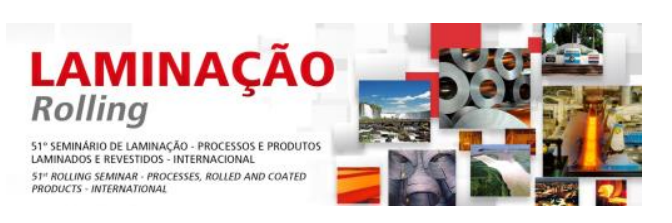

A fase $\zeta$ surge em colônias de grãos, simultaneamente às formações da fase $\Gamma_{1}$ e da camada inibidora Fe/Al. Como não existe equilíbrio termodinâmico entre $\Gamma_{1}$ e o líquido, ou entre $\Gamma 1$ e $\zeta$, o surgimento de $\Gamma$ exigirá, necessariamente, a formação de $\delta$. Da mesma forma não existe equilíbrio entre $\delta$ e líquido, fazendo com que a fase $\delta$ se forme na base de $\zeta$, assumindo o mesmo aspecto morfológico de $\zeta$ durante a solidificação (bastonetes).

Ao final do processo de transformação a fase $\zeta$ permanece na parte superior da região cristalizada, em contato com o líquido saturado em $\mathrm{Fe}$, e por isso, constituindo-se em uma camada descontínua. Abaixo, formam-se as fases $\delta$ e $\Gamma$. Contudo, o que na análise da seção do revestimento, via MEV, aparentemente é uma única fase, é um conjunto de pequenos cristais com fases distintas. Ou seja, embora existam camadas do revestimento com maior concentração de determinada fase, conforme citado acima, não existe uma interface plana e bem definida entre elas, podendo haver cristais de todas as fases ao longo de todo o revestimento.
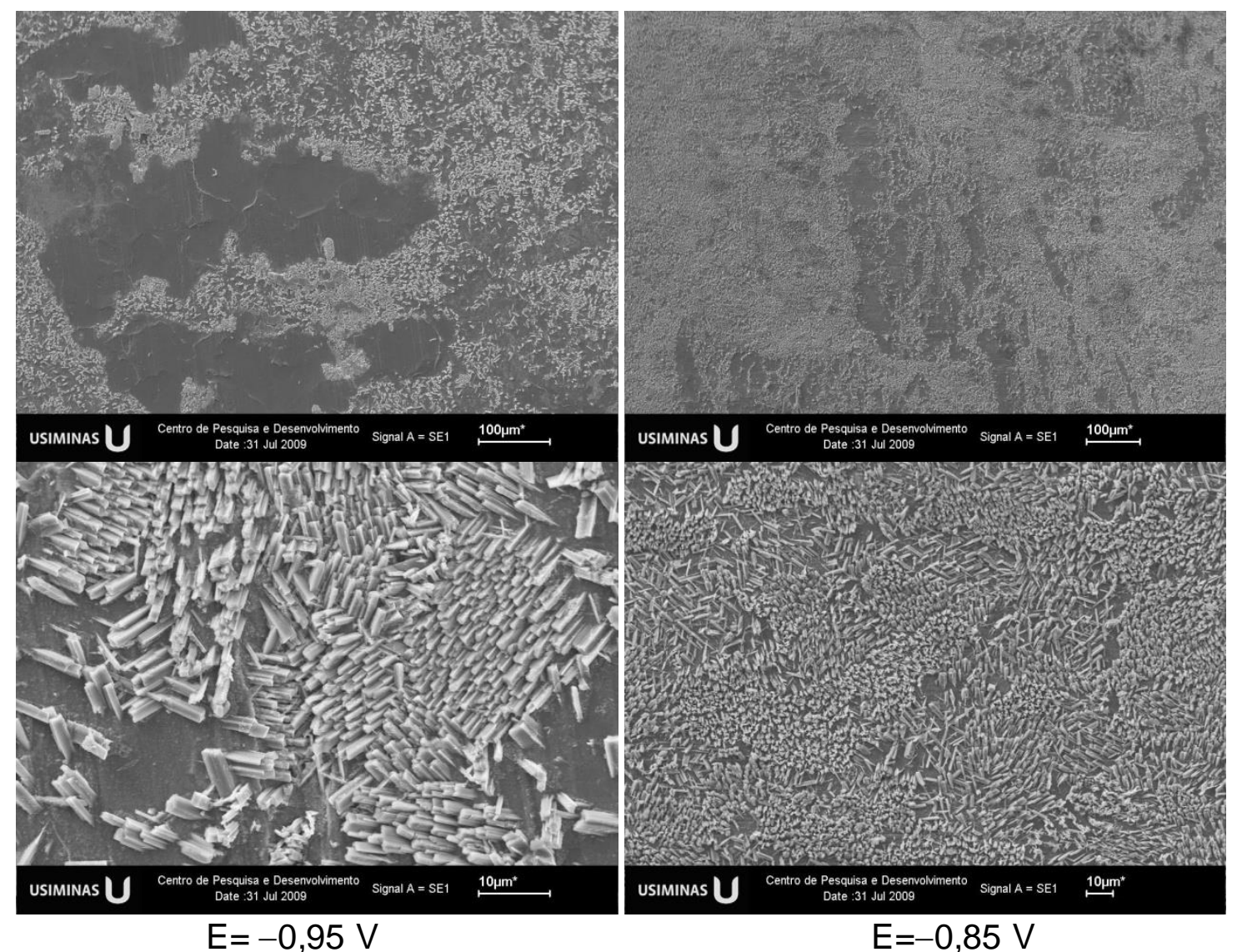

Figura 4. Morfologia de cristais Fe-Zn após dissoluções eletroquímicas parciais.

\subsection{Ciclo de Galvannealing com Temperatura de $530^{\circ} \mathrm{C}$}

Nas figuras 5 e 6 são mostrados, respectivamente, micrografias e perfis de concentração de $\mathrm{Fe}$ das seções dos revestimentos ao longo do ciclo de galvannealing realizado com temperatura inicial de $530^{\circ} \mathrm{C}$. Imediatamente após esse aquecimento ( $\mathrm{t}=0 \mathrm{~s}$ ) não há energia para a ocorrência de outbursts. De acordo com Mataigne [4], a temperatura de $530^{\circ} \mathrm{C}$ é baixa para ativar a difusão de Zn dentro dos contornos de grãos ferríticos. Contudo, já são nucleados, juntos à interface com o aço, cristais das fases $\delta$ e $\Gamma$, sendo a maior proporção de fase $\delta$. A presença da

* Contribuição técnica ao $51^{\circ}$ Seminário de Laminação - Processos e Produtos Laminados e Revestidos, 28 a 31 de outubro de 2014, Foz do Iguaçu, PR, Brasil. 


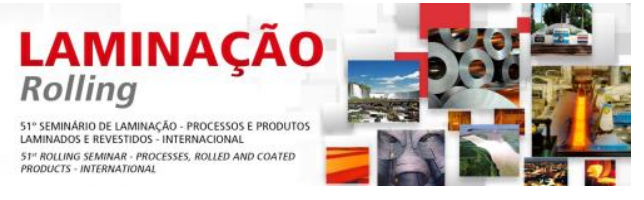

fase $\Gamma 1$ se limita à primeira camada de revestimento $(0,5 \mu \mathrm{m}$ de espessura). A fase $\delta$ possui uma espessura média de $1,5 \mu \mathrm{m}$, sendo que na camada superior $(0,5 \mu \mathrm{m})$ estarão presentes pequenos cristais da fase $\zeta$. Esses resultados diferem dos obtidos por Lin e Meshii [5], que identificaram apenas as fases $\delta(83 \%)$ e $\Gamma_{1}(17 \%)$ nos revestimentos GA formados sobre aços refosforados.

À medida que o tratamento térmico prossegue, aos $6,2 \mathrm{~s}$ as três fases crescem rapidamente em direção à superfície da camada de revestimento, em detrimento da fase líquida. Surgem as reações de outbursts. Nessa condição, a interface substrato/revestimento se torna bastante heterogênea, com regiões com diferentes intensidades dessas reações e outras isentas delas. Uma vez nucleados, os outbursts passam a influenciar todo o processo de formação das fases $\mathrm{Fe}-\mathrm{Zn}$, promovendo um crescimento mais acentuado delas. Associando-se a essas características o fato de nessa etapa do tratamento surgirem os outbursts, confirmase que essas formações se constituem, basicamente, da fase $\delta$, margeada na superfície por cristais da fase $\zeta$, e na base por uma mistura de fases $\Gamma_{1}$ e $\delta$. O rápido crescimento da fase $\zeta$ advém do fato de não existir equilibrio termodinâmico entre a fase $\delta$ dos outbursts e o zinco líquido, nucleando rapidamente a fase $\zeta$.

Aos 13,2 $\mathrm{s}$ de tratamento térmico as espessuras das três fases aumentam, além da completa transformação de $\delta$ em $\Gamma_{1}$ na camada interfacial com o substrato. Contudo, o revestimento ainda não se encontra completamente transformado.
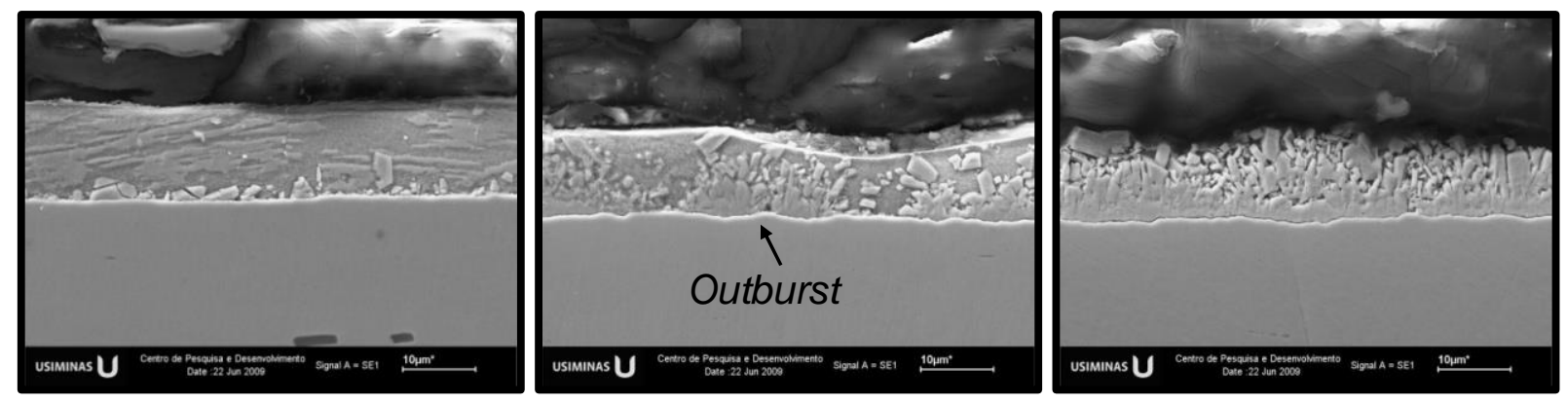

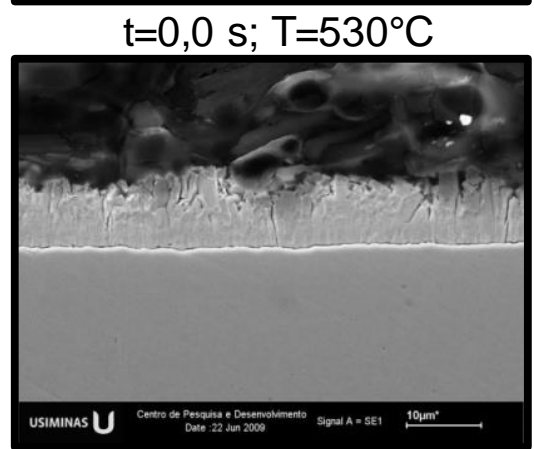

$\mathrm{t}=16,0 \mathrm{~s} ; \mathrm{T}=450^{\circ} \mathrm{C}$

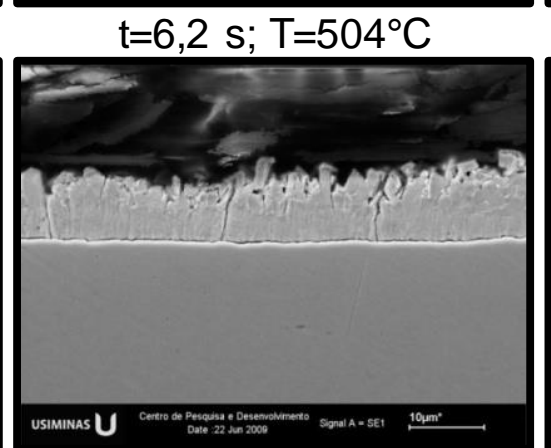

$\mathrm{t}=22,7 \mathrm{~s} ; \mathrm{T}=424^{\circ} \mathrm{C}$

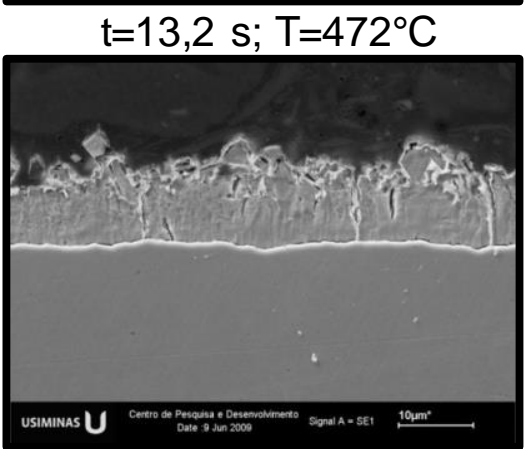

$\mathrm{T}=25^{\circ} \mathrm{C}$

Figura 5. Micrografias de seção dos revestimentos formados sobre aço $\mathrm{BH}$ ao longo do ciclo de galvannealing com $530^{\circ} \mathrm{C}$.

* Contribuição técnica ao $51^{\circ}$ Seminário de Laminação - Processos e Produtos Laminados e Revestidos, 28 a 31 de outubro de 2014, Foz do Iguaçu, PR, Brasil. 


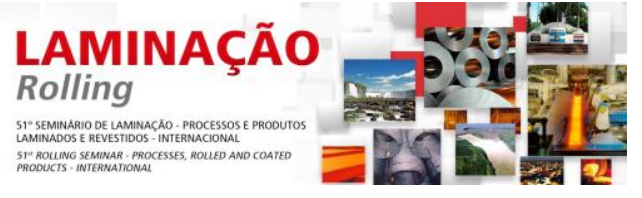

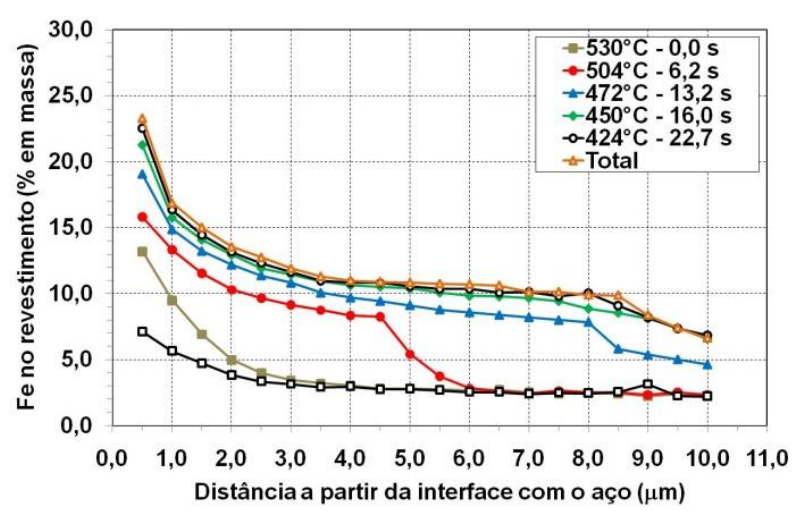

Figura 6. Perfis de concentração de Fe na seção de revestimentos formados sobre aço $\mathrm{BH}$ durante o tratamento a $530^{\circ} \mathrm{C}$.

Somente aos $16,0 \mathrm{~s}$ de tratamento é que as fases cristalizadas $\zeta$ e $\delta$ alcançam a superfície, com a completa solidificação do revestimento, e surge a fase $\Gamma$, na interface com 0 substrato. Além do surgimento da fase $\Gamma$ na base da camada, há também o crescimento da fase $\Gamma 1$ e da fase $\delta$. Entretanto, $\zeta$ começa a descrescer em espessura de camada. Contudo, ainda se nota um revestimento bastante irregular, com cristais ainda na forma de bastões e com aspecto de depressões.

Somente aos 22,7 s de tratamento é que o revestimento assume o aspecto morfológico de uma camada completamente transformada. Entretanto, com uma superfície bastante heterogênea e irregular, atípica do revestimento GA, denotando regiões com crescimento heterogêneo das fases Fe-Zn. Após a completa solidificação do revestimento, há uma estabilização da fase $\Gamma 1$ e uma redução da espessura de $\zeta$. Com o prosseguimento do processo difusional, o enriquecimento em Fe nas camadas de revestimento produz um aumento na proporção de fase $\Gamma$, que cresce junto à base consumindo $\Gamma 1$.

\subsection{Ciclo de Galvannealing com Temperatura de $545^{\circ} \mathrm{C}$}

Nas figuras 7 e 8 são mostrados, respectivamente, micrografias e perfis de concentração de $\mathrm{Fe}$ das seções dos revestimentos ao longo do ciclo de galvannealing realizado com temperatura de $545^{\circ} \mathrm{C}$. A formação dos compostos intermetálicos Fe-Zn se inicia imediatamente após o aquecimento ( $\mathrm{t}=0 \mathrm{~s})$, através das reações de outbursts, constituindo uma camada de fases $\Gamma 1 \square, \delta$ e $\zeta$. A fase $\Gamma 1 \square$ com uma proporção média de $12 \%$, localizada até $0,5 \mu \mathrm{m}$ junto à base do revestimento; a fase $\zeta$ com uma proporção de $8 \%$, a $1,5 \mu \mathrm{m}$ na superfície da camada; e a fase $\delta$, com aproximadamente $3,0 \mu \mathrm{m}$ de espessura, iniciando-se junto à base, e com uma proporção de $80 \%$. Rapidamente se constitui em uma camada de cristais $\mathrm{Fe}-\mathrm{Zn}$, mais heterogênea quanto ao tamanho, forma e áreas de adensamento de cristais do que a obtida no pote de $\mathrm{Zn}$. Os cristais são pequenos, segmentados (com muitas trincas), e possuem formatos diversos, evidenciando as heterogeneidades da interface e do processo de formação desse revestimento.

A maior elevação na concentração de Fe ocorre até $6,8 \mathrm{~s}$, quando a formação do revestimento prossegue rapidamente, embora junto à superfície sejam observadas formações cristalinas descontínuas, ainda em forma de bastões. $O$ enriquecimento em $\mathrm{Fe}$ é intenso pela existência de uma camada de fase ainda líquida (difusão na interface sólido/líquido), e com menor teor de Fe que nas fases cristalizadas.

Já com $12,9 \mathrm{~s}$, ocorre a completa transformação do revestimento, que adquire aspecto e composição bastante semelhantes à do revestimento completamente

* Contribuição técnica ao $51^{\circ}$ Seminário de Laminação - Processos e Produtos Laminados e Revestidos, 28 a 31 de outubro de 2014, Foz do Iguaçu, PR, Brasil. 


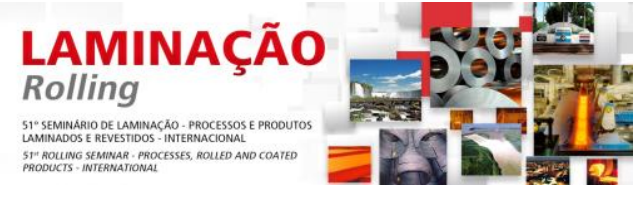

tratado, observado na amostra final. Nessa condição surge a fase $\Gamma$ junto à interface com o substrato. Uma vez formada, $\Gamma$ cresce em direção a $\Gamma$, absorvendo-a na base do revestimento. A fase $\delta$, que é a que mais cresce em função de ter-se nucleado através de outbursts, passa a ocupar a maior parte da camada galvanizada, chegando aos $12,9 \mathrm{~s}$ a ocupar $90,0 \%$ da espessura da camada e aos $22,5 \mathrm{~s}, 95,0 \%$. O crescimento de $\Gamma 1$ também é proeminente nesse tratamento, crescendo até a completa solidificação do revestimento, quando alcança aproximadamente $35 \%$ da espessura da camada.
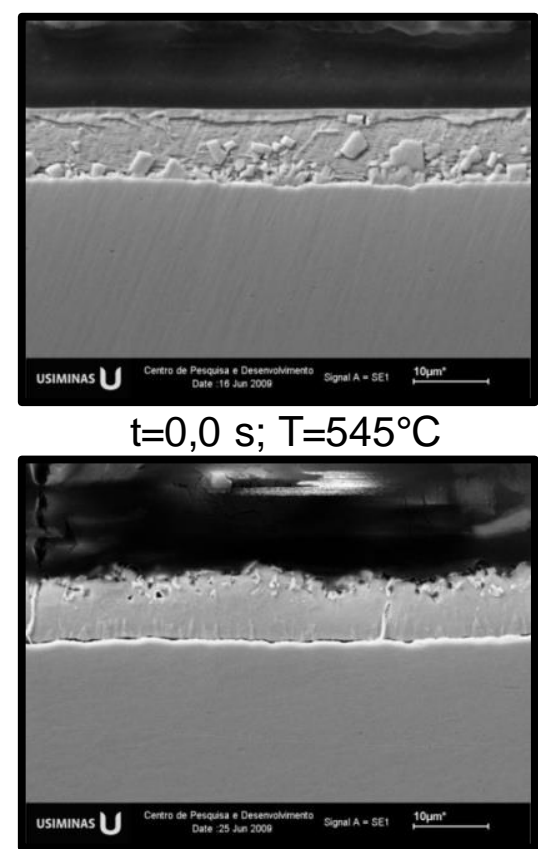

$\mathrm{t}=22,5 \mathrm{~s} ; \mathrm{T}=454^{\circ} \mathrm{C}$
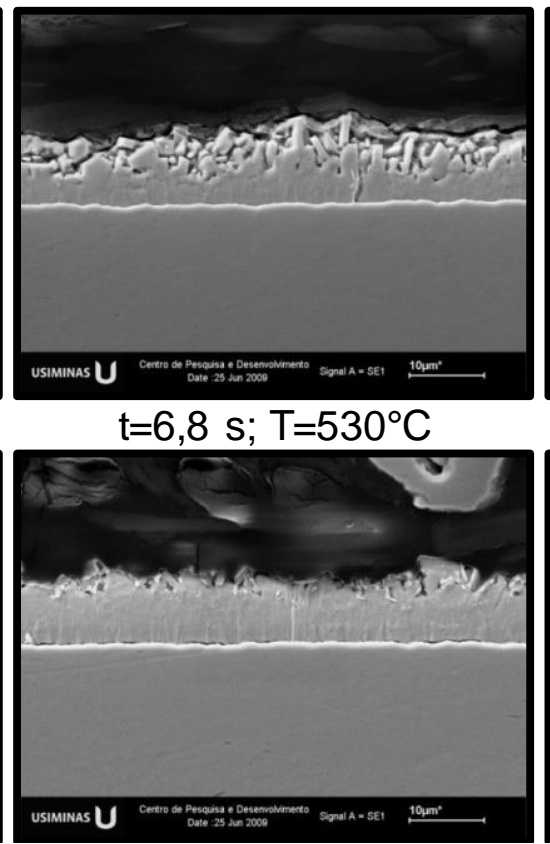

$\mathrm{t}=25,3 \mathrm{~s} ; \mathrm{T}=440^{\circ} \mathrm{C}$

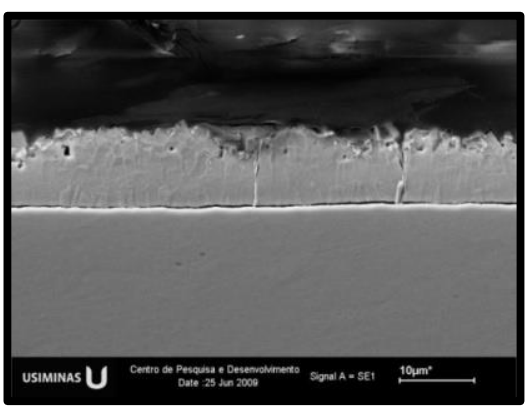

$\mathrm{t}=12,9 \mathrm{~s} ; \mathrm{T}=499^{\circ} \mathrm{C}$

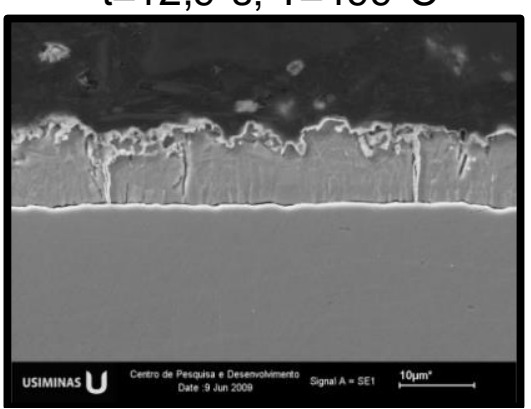

$\mathrm{T}=25^{\circ} \mathrm{C}$

Figura 7. Micrografias de seção dos revestimentos formados sobre o aço $\mathrm{BH}$, durante o ciclo de galvannealing com $545^{\circ} \mathrm{C}$.

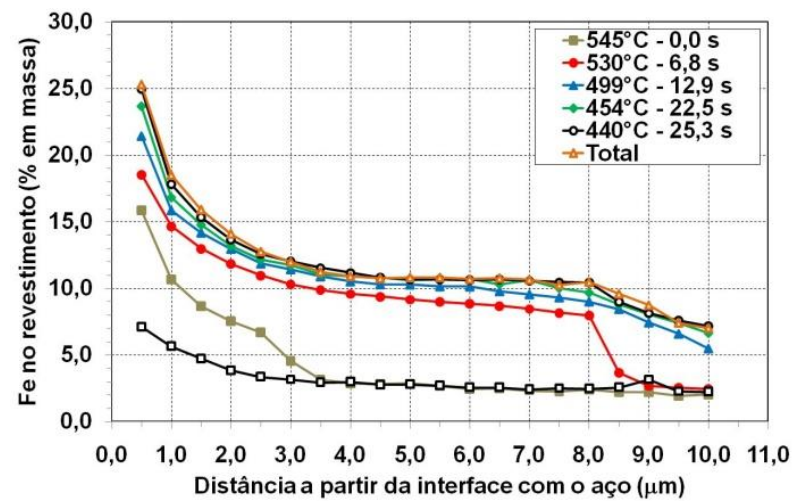

Figura 8. Perfis de concentração de Fe na seção de revestimentos formados sobre aço $\mathrm{BH}$, durante o tratamento a $545^{\circ} \mathrm{C}$.

Os perfis de concentração de Fe ao longo das espessuras de diferentes formações cristalinas Fe-Zn, não completamente transformados (amostras com $0 \mathrm{~s}$ e 6,8 $\mathrm{s}$ de processamento) são mostrados na figura 9. Nota-se imediatamente após o aquecimento, que a estrutura do revestimento já é extratificada, composta de uma camada inferior com as fases $\Gamma_{1}$ e $\delta$ (teores de Fe próximos de 16,0\%). Na região intermediária, e em maior proporção, estão os cristais de $\delta$ e, no topo do revestimento, cristais de fase $\zeta$. 


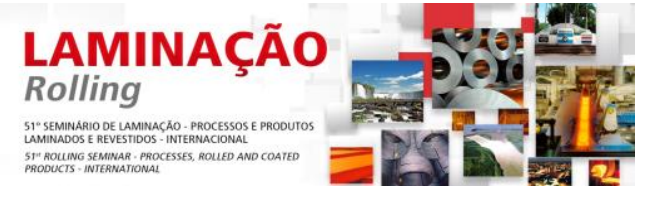

Tanto as maiores formações, que são outbursts recém nucleados (formados devido a existência de equilíbrio termodinâmico entre a fase $\delta$ e o líquido), quanto as menores, são constituídas das fases $\Gamma 1, \delta$ e $\zeta$ A mudança de fase ocorre pelo enriquecimento em $\mathrm{Fe}$ a partir da base do cristal. Uma vez alcançada a concentração mínima para formação da fase, o cristal original se rompe, havendo um destacamento de suas bordas, formando um novo cristal menos rico em $\mathrm{Fe}$ (figura 9).

Portanto, os primeiros cristais a se formarem, ainda durante o aquecimento indutivo, são os das fases $\Gamma_{1}(\sim 0,5 \mu \mathrm{m}$, junto à base do revestimento), $\delta(\sim 3,0 \mu \mathrm{m}$, iniciandose junto à base) e $\zeta(\sim 1,5 \mu \mathrm{m}$, na superfície da camada). Com o prosseguimento do tratamento térmico percebe-se, já aos $6,8 \mathrm{~s}$ de tratamento térmico, a fase $\Gamma$ junto à interface com o substrato. Uma vez formado, $\Gamma$ cresce em direção a $\Gamma$, absorvendoa na base do revestimento.

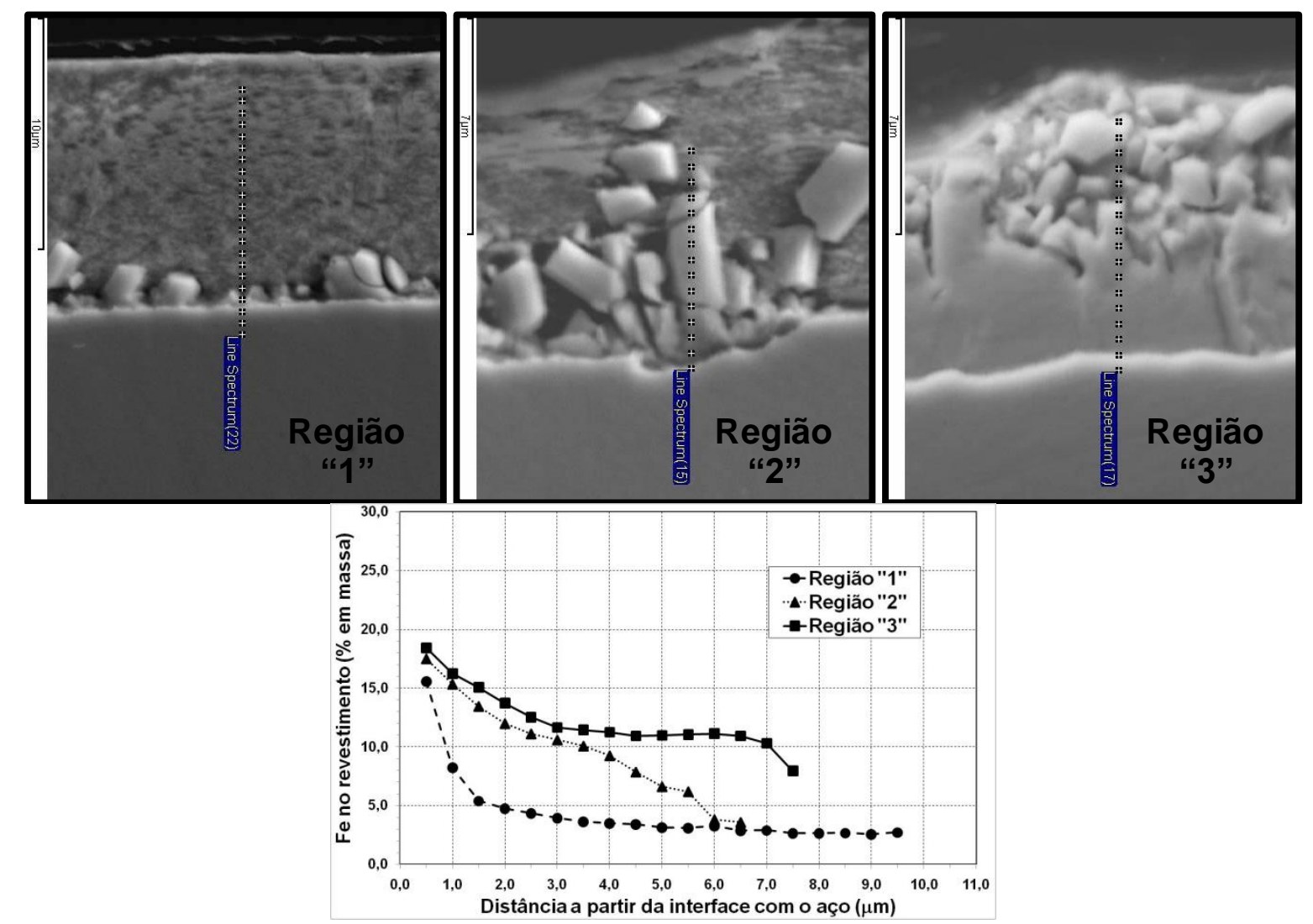

Figura 9. Perfis de concentração de Fe ao longo de diferentes formações cristalinas Fe-Zn.

$\mathrm{Na}$ figura 10 são mostrados aspectos morfológicos observados via MEV, nas camadas remanescentes do revestimento, após dissoluções eletroquímicas parciais. No início desse ciclo de galvannealing a maior parte dos cristais já se transformou e alterou seu formato. No topo da camada cristalizada, observada após a retirada da camada de $\mathrm{Zn}$ puro, percebem-se cristais poliédricos e hexagonais de fase $\delta$ juntamente com os da fase $\zeta$, com formato colunar de base quadrada.

Os cristais de $\zeta$ não obedecem a nenhum tipo de orientação evidente. Porém, alguns cristais de $\delta$, principalmente os maiores, parecem possuir alguma orientação. A explicação pode estar associada ao fato dos maiores cristais de $\delta$, que possuem orientação, serem formados a partir do substrato; os demais, menores e sem orientação, formados sobre a face de outros de $\delta$, o mesmo ocorrendo para os de $\zeta$.

* Contribuição técnica ao $51^{\circ}$ Seminário de Laminação - Processos e Produtos Laminados e Revestidos, 28 a 31 de outubro de 2014, Foz do Iguaçu, PR, Brasil. 
Com a temperatura de aquecimento a $580^{\circ} \mathrm{C}$, o aporte térmico se torna tão elevado que as reações de outbursts não são mais observadas, indiferente da intensidade com que possam ocorrer. A fase $\square$ se forma muito rapidamente, imediatamente após o aquecimento indutivo, aumentando a propensão à ocorrência de desplacamento.

\section{REFERÊNCIAS}

1 Barbosa AHA, Bouças CHS, Zacarias JJ; Vieira RR. Estudo da influência da temperatura no induction heating sobre a qualidade dos revestimentos galvanizados a quente, Relatório do Centro de Pesquisa da Usiminas, Março, 2007.

2 Barbosa AHA. Efeito das condições de galvannealing na qualidade do revestimento galvanizado a quente GA formado sobre aços de alta resistência contendo $P$ e $B$, Tese de doutorado, Belo Horizonte: Universidade Federal de Minas Gerais, 2010.

3 Guttmann M. Diffusive phase transformation in hot dip galvanizing, Materials Science Forum, 1994, v. 155-156, p. 527-548.

4 Mataigne JM. Key mechanisms in galvanization of steel sheets, 7th International Conference on Zinc and Zinc Alloy Coated Steel Sheet, Galvatech'07, ISIJ, 2007, p.333-338.

5 Lin CS, Meshii M. The effect of steel chemistry on the formation of Fe-Zn intermetallic compounds of galvanneal-coated steel sheets, Metallurgical and Materials Transactions B, 1994, v.25b, p.721-730. 